\title{
Morphological Transformation of Synaptic Terminals of a Phasic Motoneuron by Long-Term Tonic Stimulation
}

\author{
G. A. Lnenicka, H. L. Atwood, and L. Marin \\ Department of Physiology, University of Toronto, Toronto, Ontario M5S 1A8, Canada
}

In vivo stimulation of a relatively "silent" phasic crayfish motoneuron changes the ultrastructure of its synaptic terminals to a more tonic phenotype. The closer muscle of the crayfish claw is supplied by only 2 excitatory motoneurons, one of which is phasic and the other tonic. The ultrastructures of conditioned phasic, unconditioned phasic, and tonic motor terminals were compared. The terminals of the tonic motor axon were larger in cross-sectional area, had larger mitochondria, greater synaptic contact area, and were more varicose than unconditioned phasic terminals. Following long-term tonic stimulation of the phasic axon, its terminals became more varicose, mitochondrial crosssectional area more than doubled, and synapses and mitochondria came into closer proximity, although mean terminal crosssectional area did not change. Thus, the conditioned phasic terminals became more similar to those of the tonic motor axon. These changes in ultrastructure correlate with, and may be causally linked to, previously reported changes in neuromuscular synaptic physiology produced by in vivo tonic stimulation of this motoneuron. We conclude that the ongoing level of impulse activity can affect the ultrastructural differentiation of synaptic terminals and synapses of the phasic motoneuron.

Structural changes at synapses in response to long-tcrm alterations in activity have been previously examined for their possible role in synaptic plasticity (Bailey and Chen, 1983) and synaptic differentiation during development (Garey and Pettigrew, 1974; Greenough et al., 1978; Sirevaag and Greenough, 1985). Many of these studies have not utilized a well-defined system in which the normal in vivo activity of identified synapses can be monitored and specifically altered. For this reason, we have studied the crustacean neuromuscular junction. Crustacean muscles are supplied by relatively few identified motoneurons; the activity of identified motoneurons can be monitored and altered in vivo; and crustacean peripheral synapses are similar in physiology to many central synapses.

In general, crustacean motoneurons can be classified as phasic or tonic on the basis of their normal pattern of activity (Atwood, 1973). Associated with these differences in activity are differences in neuromuscular synaptic physiology and synaptic terminal morphology. Generally, phasic motoneurons release large amounts of transmitter initially but show dramatic synaptic depression during repetitive activation. Conversely, tonic motoneurons release less transmitter initially but show little depression; facilitation of transmitter release usually occurs during repetitive activation.

Differences in motor terminal ultrastructure have been re-

Received Oct. 7, 1985; revised Jan. 20, 1986; accepted Jan. 22, 1986.

This work was supported by the MRC and NSERC. We would like to thank Peter Szacki for writing software for the digitization and reconstruction of terminal structure, Sophie Papas and Sabina Laske for tracing micrographs, and Marianne Hegstrom-Wojtowicz for assisting with the figures.

Correspondence should be addressed to Dr. H. L. Atwood at the above address. Copyright (C 1986 Society for Neuroscience $0270-6474 / 86 / 082252-07 \$ 02.00 / 0$ ported for tonic and phasic motoneurons in lobster (Hill and Govind, 1981), locust (Titmus, 1981), and crab (Atwood and Jahromi, 1978; Atwood and Johnston, 1968). Some of these differences appear to be linked to the differences in synaptic physiology of tonic and phasic motoneurons. In particular, the greater mitochondrial content and synaptic vesicle population of tonic motor terminals could be related to their resistance to depression (Atwood, 1976; Atwood and Jahromi, 1978; Atwoud and Johnston, 1968).

We have previously reported that the neuromuscular physiology of a phasic motoneuron - the "fast" axon innervating the crayfish closer muscle-becomes similar to that of a tonic motoneuron after in vivo chronic stimulation. After 2 weeks of intermittent tonic stimulation, initial release of transmitter and synaptic depression during repetitive stimulation decrease (Lnenicka and Atwood, 1985a). In order to determine whether morphological changes could be responsible for this change in physiology, the ultrastructure of unconditioned and conditioned phasic axon terminals was quantified and compared, using serial-section electron microscopy. In addition, terminals of the tonic ("slow") motor axon found on the same fibers were included in the comparison in order to quantify differences between normally tonically active and phasically active motoncurons innervating the same muscle fibers. We found that tonic stimulation of the fast axon shifts the structure of its motor terminals toward the phenotype of the slow axon. The relationship of these structural alterations to the previously reported changes in physiology is discussed.

A brief preliminary report has been presented (Atwood et al., 1985).

\section{Materials and Methods}

Stimulation and recording electrodes were implanted into claws of crayfish (Procambarus clarkii) for in vivo stimulation and monitoring of the fast axon as previously described (Lnenicka and Atwood, 1985a).

In each of 2 crayfish $(2.5 \mathrm{~cm}$ carapace length), the fast axon in one claw was stimulated daily at $5 \mathrm{~Hz}$ for $2 \mathrm{hr}$ over a period of 2 weeks. Since crayfish claws are symmetrical, the other claw was used as a control. This regimen has been shown to decrease the low-frequency $(0.01 \mathrm{~Hz})$ transmitter release by $40-50 \%$ and to increase the fatigue resistance of the terminals during $5 \mathrm{~Hz}$ stimulation (Lnenicka and Atwood, 1985a).

In order to identify unambiguously the fast and slow terminals for electron microscopy, they were labeled through HRP uptake during selective stimulation (Holtzman et al., 1971; Thompson and Atwood, 1984). Branches of the common inhibitor axon, which also supplies this muscle (Wiens, 1985), were identified from the irregular shape of the included synaptic vesicles and lightly staining synaptic membranes (Atwood and Morin, 1970; Uchizono, 1965).

One day after the final in vivo stimulation, conditioned (stimulated) and contralateral control (unstimulated) claws were removed. The closer muscle was exposed and presoaked in the bathing medium (2\% HRP in van Harreveld's solution) for $30 \mathrm{~min}$. In 1 animal, the slow terminals were labeled in both claws, while in another, the fast terminals were labeled. This was accomplished through selective stimulation of the fast or slow axon with a suction electrode placed against the nerve in the 
Table 1. Measurements of synapses and terminals

\begin{tabular}{|c|c|c|c|c|c|c|}
\hline & Terminal & & & Synapses & & \\
\hline & $\begin{array}{l}\mathrm{CSA} \\
\left(\mu \mathrm{m}^{2}\right)\end{array}$ & $\begin{array}{l}\text { Perimeter } \\
(\mu \mathrm{m})\end{array}$ & $\begin{array}{l}\text { Varicosities/ } \\
\mu \mathrm{m} \text { terminal } \\
\text { length }\end{array}$ & $\begin{array}{l}\text { Total } \\
\text { synaptic } \\
\text { contact } \\
\text { area/ } \mu \mathrm{m} \\
\text { length of } \\
\text { terminal } \\
\left(\mu \mathrm{m}^{2}\right)\end{array}$ & $\begin{array}{l}\text { Individual } \\
\text { synaptic } \\
\text { contact area } \\
\left(\mu \mathrm{m}^{2}\right)\end{array}$ & $\begin{array}{l}\text { Synapses/ } \\
\mu \mathrm{m} \text { length } \\
\text { of } \\
\text { terminal } \\
(n)\end{array}$ \\
\hline Fast control & $\begin{array}{r}0.551 \\
\pm 0.167 \\
(n=9)\end{array}$ & $\begin{array}{r}2.542 \\
\pm 0.387 \\
(n=9)\end{array}$ & $\begin{array}{c}0.04 \\
\pm 0.03 \\
(n=9)\end{array}$ & $\begin{array}{r}0.247 \\
\pm 0.044 \\
(n=9)\end{array}$ & $\begin{array}{l}0.414 \\
\mathrm{SD}=0.306 \\
(n=31)\end{array}$ & $\begin{array}{c}0.64 \\
\pm 0.11 \\
(n=9)\end{array}$ \\
\hline Fast conditioned & $\begin{array}{r}0.553 \\
\pm 0.141 \\
(n=9)\end{array}$ & $\begin{array}{r}2.666 \\
\pm 0.374 \\
(n=9)\end{array}$ & $\begin{array}{c}0.14 \\
\pm 0.04^{*} \\
(n=9)\end{array}$ & $\begin{array}{r}0.629 \\
\pm 0.883 \\
(n=9)\end{array}$ & $\begin{array}{l}0.872 \\
\mathrm{SD}=1.809 \\
(n=40)\end{array}$ & $\begin{array}{r}0.60 \\
\pm 0.06 \\
(n=9)\end{array}$ \\
\hline Slow & $\begin{array}{c}1.120 \\
\pm 0.273^{*} \\
(n=12)\end{array}$ & $\begin{array}{r}3.572 \\
\pm 0.416 \\
(n=12)\end{array}$ & $\begin{array}{l}0.13 \\
\pm 0.04 \\
(n=12)\end{array}$ & $\begin{array}{c}0.958 \\
\pm 0.247^{*} \\
(n=12)\end{array}$ & $\begin{array}{l}1.189^{*} \\
\mathrm{SD}=1.061 \\
(n=60)\end{array}$ & $\begin{array}{c}0.79 \\
\pm 0.13 \\
(n=12)\end{array}$ \\
\hline
\end{tabular}

All values except those for individual synaptic contact area were based on mean values determined for each series of sections. Mean and SEM are given, except for individual synaptic contact area, for which SD is given. Asterisk indicates the value is significantly different from the fast axon control at the 0.05 level according to a 2 -tailed Mann-Whitney $U$ test.

meropodite. The stimulation was monitored by recording intracellularly the evoked synaptic activity in distal muscle fibers (strongly innervated by the fast axon) and proximal muscle fibers (strongly innervated by the slow axon).

After this period of stimulation, the preparation was rested for 30 min in the bathing solution. The muscle was then prefixed overnight at $4^{\circ} \mathrm{C}$ in $2.5 \%$ glutaraldehyde in $0.1 \mathrm{M}$ sodium cacodylate buffer, $\mathrm{pH} 7.4$. After prefixation, the surface layer of fibers in the distal third of the muscle was removed, processed for HRP reaction product (Itoh et al., 1979 ), and postfixed in $2 \%$ osmium tetroxide. After embedding the fibers in Epon-Araldite, sections were cut and mounted on single-slot Formvar-coated grids; they were viewed with either a Philips $201 \mathrm{C}$ or Jeol $100 \mathrm{C} \times$ electron microscope.

These muscle fibers were searched for synaptic terminals. When a fast axon terminal was identified, it was followed in serial sections and photographed. Terminal structures were measured using a digitizing pad. If there was a slow axon terminal adjacent to the fast terminal, it was also measured.

In tctal, serially sectioned segments from 9 experimental (conditioned) fast axon terminals (649 sections) and 9 control fast axon terminals ( 530 sections), each located on a separate randomly selected muscle fiber, were measured. In addition, 12 serially sectioned slow axon terminals were measured ( 835 sections). Mean values of terminal cross-sectional area and mitochondrial cross-sectional area were determined for each series. Because of the skewness of some of the distributions (especially of values from the control fast axon terminals), all statistical tests were nonparametric. The Mann-Whitney $U$ test (MWU) was used to compare population means. The Wilcoxon matched-pairs test was used to compare the mean values of synaptic area and synaptic density for bottlenecks and varicosities found on the same series of sections.

Terminal varicosities were defined by searching along each series until a point was reached in which a 5 -fold change in terminal cross-sectional area (CSA) had occurred; this defined the beginning of a varicosity. A 5-fold decrease in CSA denoted the end. In order to smooth out sectionto-section variability along the terminal, CSA values were the mean of 3 successive sections.

\section{Results}

The fast axon of the crayfish closer muscle is normally silent, firing approximately once every $2 \mathrm{hr}$ in the laboratory environment (Pahapill et al., 1985). Its synaptic properties are typical of a phasic motoneuron: Large amounts of transmitter are released initially, and prominent synaptic depression occurs during repetitive stimulation (Lnenicka and Atwood, 1985a). In the region of the closer muscle selected for study, the slow axon produces small EPSPs at low frequencies $(<0.5 \mathrm{mV}$ at $1 \mathrm{~Hz})$; however, during high-frequency activation these EPSPs strongly facilitate. This axon is often normally active at moderate $(10-$ $20 \mathrm{~Hz}$ ) to high $(100-200 \mathrm{~Hz})$ frequencies for periods of seconds to minutes.

\section{Terminal morphology and organization}

The mean terminal cross-sectional area was significantly greater for the slow axon than for the fast axon (Table 1). This observation is in agreement with previous studies of fast and slow motor axon terminals (Hill and Govind, 1981; Titmus, 1981).

The mean terminal CSA and perimeter for conditioned fast axon terminals were almost identical with those of controls. The control fast axon terminals were relatively uniform in CSA, consistent with earlier studies of crustacean fast axon terminals (Atwood and Jahromi, 1978). However, the conditioned fast axon terminals were more varicose, resembling the slow axon terminals (Fig. 1). This difference was quantified by searching each series for 5 -fold increases or decreases in CSA and dividing the terminal up into varicosities and bottlenecks accordingly (Table 1).

The varicosities in conditioned fast axon terminals contain a substantial number of terminal mitochondria and synapses. Varicosities occupy only $42 \%$ of the terminal length but contain $78 \%$ of the terminal mitochondrial volume and $66 \%$ of its synaptic area. The proximity of synapses and mitochondria is increased due to their concentration in varicosities (Fig. 1). This is further demonstrated by correlating the length of synaptic contact with total mitochondrial CSA for each section. In unconditioned fast axon terminals, there is a poor correlation between the length of synaptic contact in each section and total terminal mitochondrial CSA in the same section $(r=0.05, n=$ 530). In conditioned terminals, this correlation is much stronger $(r=0.66, n=649)$.

The more frequent occurrence of synapses at varicosities results in an uneven distribution of synapses along the length of both slow axon and conditioned fast axon terminals. The synapses of the control fast axon terminals appear to be more evenly distributed (Fig. 1). Synaptic spacing was quantified by measuring the distances between the centers of adjacent synapses. 

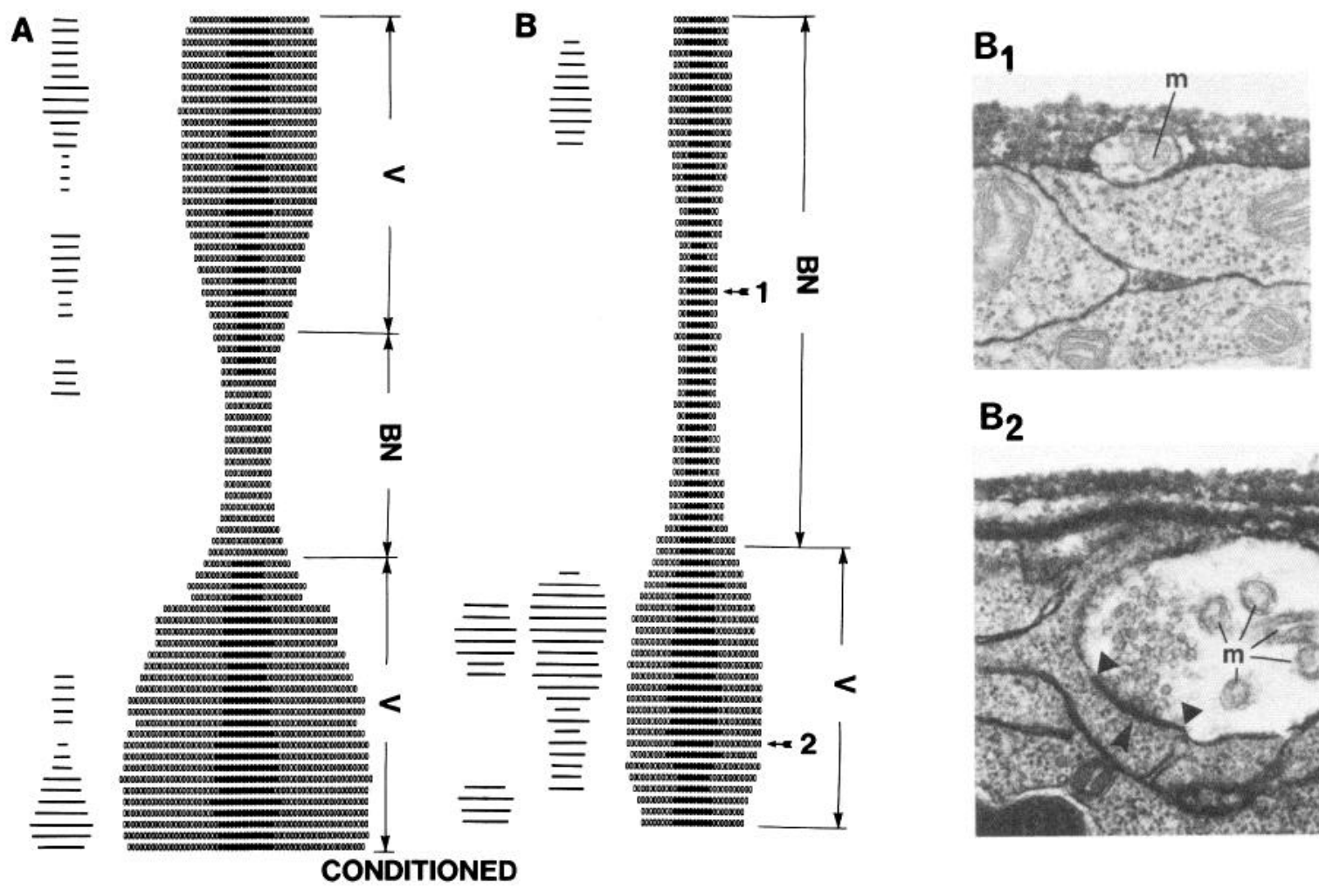

$\mathbf{B}_{2}$

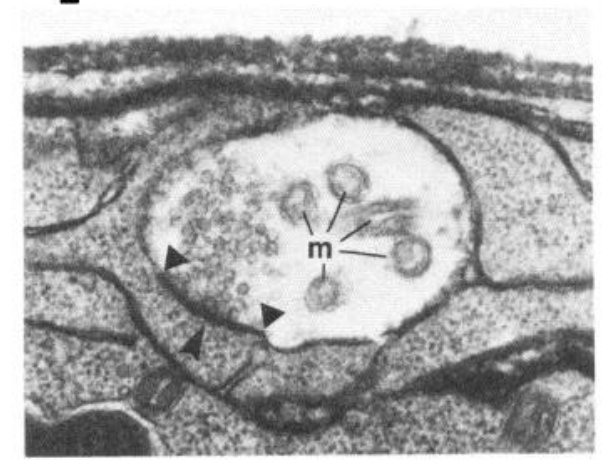

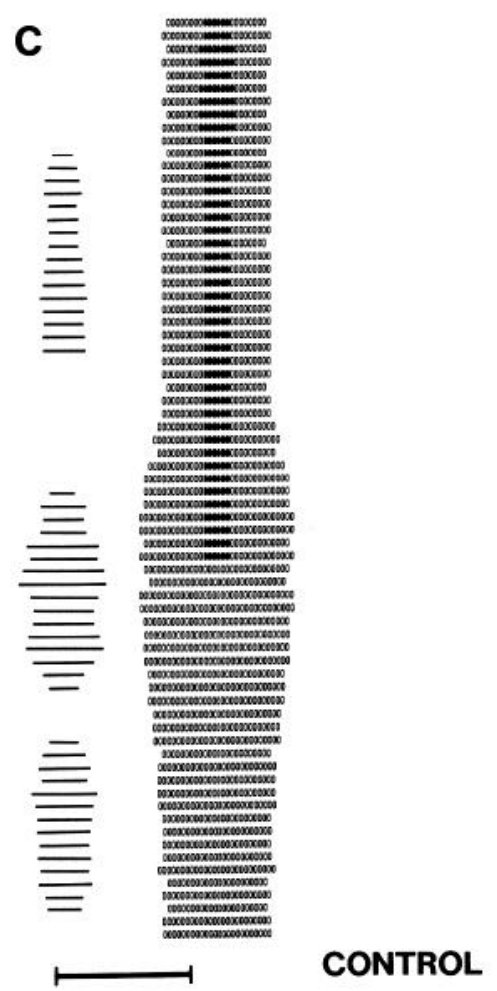



Figure 1. Schematic representation of the organization and structure of control $(C, D)$ and conditioned $(A, B)$ fast axon terminals. The equivalent terminal diameter and equivalent total mitochondrial diameter per section are represented schematically (O and $\bullet$, respectively). The horizontal lines immediately to the left represent the length of synaptic membrane per section for individual synapses. Equivalent terminal diameter was determined by calculating the diameter from the measured cross-sectional area, assuming a circular shape. Equivalent total mitochondrial diameter was found by summing all mitochondrial cross-sectional areas and then calculating diameter assuming a circular shape. The locations of bottlenecks $(B N)$ and varicosities $(V)$, based on criteria presented in Materials and Methods, are shown. For terminal $B$, representative micrographs $\left(B_{1}, B_{2}\right)$, 

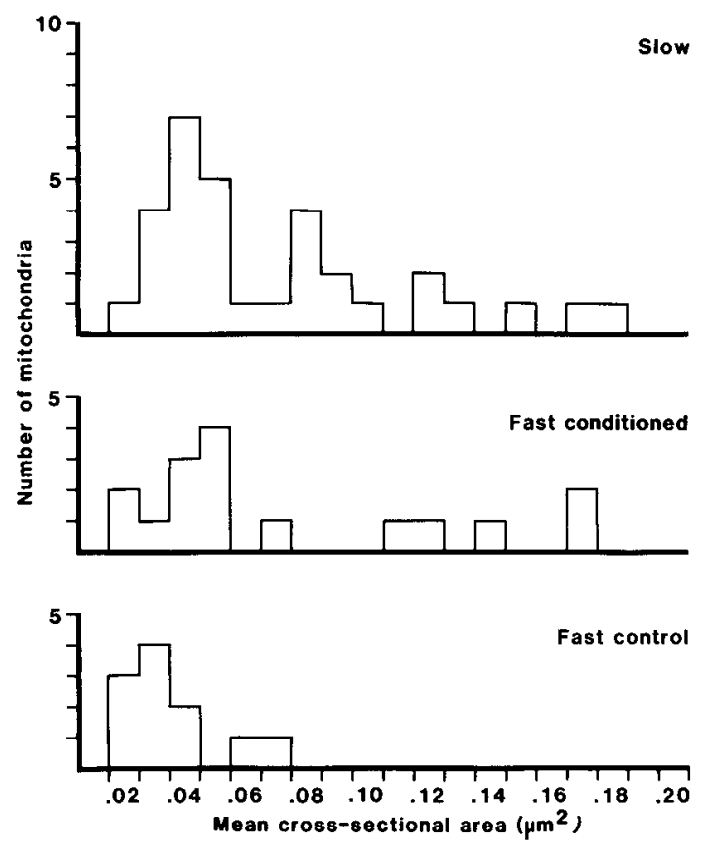

Figure 2. Mean cross-sectional area of individual terminal mitochondria. Mitochondria were followed in serial sections and their profiles traced using a digitizing pad. Their individual mean cross-sectional areas were determined and plotted in a histogram.

The synaptic intervals for the control fast axon terminals appeared normally distributcd, with $48 \%$ of the intervals falling between 1 and $2 \mu \mathrm{m}, 17 \%$ less than $1 \mu \mathrm{m}$, and $25 \%$ greater than $2 \mu \mathrm{m}$. The frequency distribution of the synaptic intervals for the slow axon terminals was significantly different from the control fast axon terminals ( $\chi^{2}$ test, $p<0.05$ ), with the highest frequency of intervals (44\%) at less than $1 \mu \mathrm{m}$. Similarly, the conditioned fast axon terminals had a higher frequency $(30 \%)$ of short synaptic intervals than the control fast axon terminals as a result of "clumping" of synapses at varicosities. However, the frequency distribution was not significantly different at the 0.05 level $\left(\chi^{2}\right.$ test $)$.

\section{Terminal mitochondria}

A comparison of mitochondrial measurements in fast axon conditioned, fast axon control, and slow axon terminals is presented in Table 2. Slow axon terminals have a 4.2-fold greater total mitochondrial volume per micron of terminal than control fast axon terminals. Chronic conditioning stimulation of the fast axon results in a 2.4-fold increase in total mitochondrial volume.

The increase in total mitochondrial volume is mainly attributed to an increase in the CSA of individual mitochondria (Fig. 2). In conditioned fast axon terminals and slow axon terminals, individual mitochondrial CSA is approximately twice that found in unconditioned (control) fast axon terminals. The number of mitochondria per micron of terminal is not significantly greater in the conditioned fast axon terminals than in controls. In slow axon terminals, the number of mitochondria is significantly greater than in control fast axon terminals.

In control fast axon terminals, mitochondria occupy $4.5 \%$ of
Table 2. Measurements of mitochondria

\begin{tabular}{cccc} 
& $\begin{array}{l}\text { Total } \\
\text { mitochondrial } \\
\text { volume/ } \mu \mathrm{m} \\
\text { terminal } \\
\left(\mu \mathrm{m}^{3}\right)\end{array}$ & $\begin{array}{l}\text { Mean CSA of } \\
\text { individual } \\
\text { mitochondria } \\
\left(\mu \mathrm{m}^{2}\right)\end{array}$ & $\begin{array}{l}\text { Mitochon- } \\
\text { dria/ } \mu \mathrm{m} \\
\text { terminal } \\
(n)\end{array}$ \\
\hline Fast control & 0.0186 & 0.0310 & 0.23 \\
& $\begin{array}{l} \pm 0.0037 \\
(n=9)\end{array}$ & $\begin{array}{l} \pm 0.0049 \\
(n=11)\end{array}$ & $\begin{array}{l} \pm 0.05 \\
(n=9)\end{array}$ \\
Fast condi- & $0.0456^{*}$ & $0.0685^{*}$ & 0.29 \\
tioned & \pm 0.0152 & \pm 0.0126 & \pm 0.09 \\
& $(n=9)$ & $(n=16)$ & $(n=9)$ \\
Slow & $0.0715^{*}$ & $0.0672^{*}$ & $0.44^{*}$ \\
& \pm 0.0190 & \pm 0.0076 & \pm 0.06 \\
& $(n=12)$ & $(n=32)$ & $(n=12)$
\end{tabular}

To determine the total mitochondrial volume per micron of terminal, total mitochondrial volume was determined for each series and divided by the length of the series. The mean CSA was also determined individually for each mitochondrion found in the terminals. The number of synapses per unit length of terminal was determined for each series of sections. Thus, in columns 1 and 3 , values of $n$ refer to the number of separate series of sections. In column $2, n$ is the number of mitochondria. Asterisk indicates the value is significantly different from the fast axon control at the 0.05 level according to a 2-tailed Mann-Whitney $U$ test. Values represent means \pm SEM.

the total terminal volume, and the correlation between terminal CSA and mitochondrial CSA per section is relatively weak $(r=$ $0.38, n=530$ ). After conditioning, mitochondria account for $9.2 \%$ of the terminal volume, and there is a stronger correlation between terminal CSA and mitochondrial CSA $(r=0.70, n=$ 649 ). Thus, in conditioned fast axon terminals, relatively more mitochondrial material is found in varicosities than in bottlenecks.

The number of mitochondria per length of terminal, and the percentage of sections containing 0,1 , or 2 separate mitochondria is very similar in conditioned and control terminals of the fast axon. Thus, it appears that the average length of individual mitochondria is not different in conditioned and control terminals. Mitochondrial length varies greatly: We observed mitochondria ranging in length from 0.5 to $>8 \mu \mathrm{m}$. This is consistent with the size of mitochondria seen with light microscopy in the axon of the homologous neuron in the American lobster (Allen et al., 1982). Since only $2.5 \%$ of scctions in control terminals, and $3.5 \%$ of sections in conditioned terminals contain 2 mitochondria, it is clear that individual mitochondria rarely overlap.

Branched mitochondria were frequently seen, especially in conditioned fast axon terminals (Fig. 1). The mitochondria of the conditioned fast axon terminals have more side branches (1.3/mitochondrion) than either fast axon controls $(0.2 / \mathrm{mito}$ chondrion) or slow axon terminals $(0.3 /$ mitochondrion $)$. This increase in the number of branches is not totally responsible for the increased mitochondrial CSA; the mean CSA of the individual mitochondrial processes is significantly greater in conditioned (mean \pm SEM, $0.0500 \pm 0.0057 \mu \mathrm{m}^{2}, n=37$ ) than in control $\left(0.0288 \pm 0.0036 \mu \mathrm{m}^{2}, n=13\right)$ fast axon terminals $(p<$ $0.05 ; \mathrm{MWU})$.

$\leftarrow$

from which measurements were made, are shown at the region of a bottleneck and a varicosity. The single mitochondrion ( $m$ ) at the bottleneck branches to form the 5 profiles seen at the varicosity. The location of a synapse is indicated by an arrow. Note the more varicose appearance of the conditioned terminals and the proximity of large mitochondrial equivalent diameters to synapses. This was a common feature of conditioned, but not of control, terminals. Calibration bars: Lower left, $2 \mu \mathrm{m}$ for synapses; $1 \mu \mathrm{m}$ for mitochondria and terminals: Upper right, $0.5 \mu \mathrm{m}$ for micrographs $B_{1}$ and $B_{2}$. 


\section{Synapses and dense bars}

Slow axon terminals have a significantly greater synaptic contact area per length of terminal than fast axon controls (l'able 1). This is mainly due to greater synaptic contact area for individual slow axon synapses; the number of synapses per micron of terminal is not significantly larger. The conditioned terminals of the fast axon show a trend toward greater synaptic contact area per length of terminal and greater individual synaptic contact area; however, the differences are not significant. There is no significant difference in the number of synapses per length of terminal for the 3 classes of terminal.

Slow axon terminals have a significantly greater percentage of their surface specialized as synaptic membrane (mean \pm SEM, $26.4 \pm 4.8 \%, n=12)$ than control fast axon terminals $(10.6 \pm$ $2.6 \%, n=9 ; p<0.05$; MWU). Conditioned terminals of the fast axon also have a greater percentage of synaptic membrane $(21.1 \pm 5.8 \%, n=9)$, although the difference between values for conditioned and control terminals is not statistically significant ( $p>0.05 ; \mathrm{MWU})$. Thus, there was a consistent tendency for the measurements in conditioned fast axon terminals to be similar to those of the slow axon terminals, even though statistical significance was not attained in the samples analyzed.

In conditioned fast axon terminals, synaptic area in varicosities is greater than in bottlenecks. However, the number of synapses per unit of membrane area is similar in varicosities $\left(0.235\right.$ synapses $/ \mu \mathrm{m}^{2}$ membrane) and bottlenecks $(0.281$ synapses $/ \mu \mathrm{m}^{2}$ membrane). The greater membrane area per length of terminal results in significantly more synapses in varicosities $(0.83 \pm 0.17 / \mu \mathrm{m}$ of terminal, $n=9)$ than in bottlenecks $(0.35 \pm$ $0.11 / \mu \mathrm{m}$ of terminal, $n=10 ; p<0.05$; Wilcoxon matched pairs, $n=6)$. Individual synapses on varicosities are significantly larger $(1.237, \mathrm{SD}=2.545, n=17)$ than those on bottlenecks (0.520, $\mathrm{SD}=0.444, n=13 ; p<0.05$; Wilcoxon matched pairs, $n=6)$.

Presynaptic dense bars [thought to be the equivalent of the synaptic "active zone" in vertebrate neuromuscular junctions (Dreyer et al., 1973; Wernig, 1976)] are small and occur infrequently in all terminals. Possibly, some of these structures may have been difficult to distinguish in this material. The number of dense bars per micron of terminal for the slow (mean $\pm S E M$, $0.40 \pm 0.08, n=12)$ and fast axon conditioned terminals $(0.48 \pm$ $0.18, n=9$ ) is not significantly different from the control fast axon terminals $(0.36 \pm 0.12, n=9 ; p>0.05$; MWU).

\section{Discussion}

\section{Terminal morphology and organization}

After in vivo stimulation the terminals become more varicose, and the synapses and mitochondria are largely located in these varicosities. It has been proposed that swellings in axons (Martinez and Friede, 1970) and dendrites (Sasaki-Sherrington et al., 1984) are produced by the accumulation of organelles, including mitochondria. Consistent with these earlier findings, we report that mitochondria enlarge after tonic in vivo stimulation and that a stronger correlation between mitochondrial CSA and terminal CSA is then observed.

Synaptic as well as nonsynaptic membrane may move to regions of terminal enlargement during in vivo stimulation. In control fast axon terminals the synapses are fairly evenly spaced along the length of the terminal. In the more varicose slow axon and conditioned fast axon terminals, the density of synapses in varicosities is similar to that in bottlenecks and, thus, the synapses are less evenly distributed. Varicosities of conditioned fast axon terminals have synapses with a larger mean surface contact area than those in bottlenecks. The above observations suggest migration of membrane to selected areas of the terminal-possibly toward sites of mitochondrial and/or synaptic enlargement.
It is interesting to note that the mitochondria in the control and conditioned fast axon terminals only overlap in approximately $3 \%$ of the sections. It appears that they sterically exclude one another from occupying the same portion of the terminal.

The close proximity of the synapses and mitochondria after in vivo stimulation may permit a continuous supply of energy to be provided to synaptic regions. Also, removal of calcium by mitochondria during synaptic activity may be enhanced (Lehninger, 1970).

The mean perimeter and CSA of the fast axon terminal does not increase after in vivo stimulation to values found in the slow axon. The amount of terminal membrane for the motoneuron may be genetically fixed or controlled by factors other than activity levels. This may limit the extent to which fast axon terminals can increase their intraterminal content of mitochondria, synaptic vesicles, and soluble proteins during increases in activity, thus limiting the range of physiological adaptation. However, the conditioning regimes employed in this study may not have extracted the maximal adaptive response from the phasic neuron.

It has been proposed that the varicose structure of motor nerve terminals in the moth Manduca sexta may be induced by the muscle (Rheuben, 1985; Schaner and Rheuben, 1985). Our data indicate that varicosities are the result of high motoneuron activity levels, probably due to an increase in the intraterminal organelles. This is based on the observations that tonic terminals are more varicose than phasic terminals, even when found on the same muscle fiber, and that an increase in activity increases the number of varicosities in phasic terminals.

\section{Mitochondria}

The mitochondrial content of various cell types has been shown to be very dynamic. In some cases, changes in total mitochondrial volume appcar to correlate with changes in cellular energy demands (for review, see Smith and Ord, 1983). For example, chronic stimulation of fast-twitch skeletal muscle results in an increase in the mitochondrial volume fraction (Eisenberg and Salmons, 1980). Our results indicate that nerve terminals can also adjust their mitochondrial content to meet increased energy demands. This apparently accounts for the greater mitochondrial content normally seen in tonic than in phasic invertebrate motor terminals, and possibly the greater oxidative enyzme activities reported for vertebrate tonic motoneurons (Sickles and Oblak, 1984). The greater mitochondrial volume per unit length of axon terminal should result in higher energy metabolism and therefore may be responsible for the resistance of tonic motor terminals and conditioned fast axon terminals to synaptic fatigue.

Mitochondria are transported in the orthograde direction in the axon by fast axonal transport (Grafstein and Forman, 1980). The increase in mitochondrial CSA that we observe in the terminals could be produced by the transport of more mitochondria into the terminals and subsequent fusion with those already present. The greater number of mitochondrial branches in the conditioned fast axon terminals suggests mitochondrial fusion. Fusion of mitochondria to form large multibranched structures has been reported for many different cell types (Frederic and Chevremont, 1952; Smith and Ord, 1983). Alternatively, the branches could be a mechanism by which active mitochondria increase their surface area for more rapid exchange of metabolites.

Increased production of mitochondrial proteins is probably involved in the increase in mitochondrial mass. Changes in cytoplasmic protein synthesis likely occur, since the majority of the mitochondrial proteins are synthesized in the cytoplasm (Schatz and Mason, 1974). Since cytoplasmic protein synthesis is confined to the cell body (Lasek and Brady, 1982), regulation of such events probably occurs there. Involvement of the cell 
body is supported by the finding that the change in physiology normally produced by long-term tonic stimulation does not occur in decentralized fast axons (Lnenicka and Atwood, 1985b).

\section{Synapses and dense bars}

The total synaptic contact per unit length of terminal was much greater for the slow than for the fast axon; this was mainly due to greater individual synapse size. Previous ultrastructural studies comparing synapses with high initial transmitter output (at poorly facilitating terminals) and those with low initial transmitter output (at highly facilitating terminals) within a single excitatory crustacean motor axon have also shown that total synaptic area per length of terminal is greater in low-output, facilitating terminals (Atwood and Marin, 1983; Govind et al., 1982). Thus, it appears that the total area of synaptic contact is not the limiting factor in the control of low-frequency transmitter release in these terminals.

Our data represent a dramatic example of the lack of a positive correlation between synaptic membrane area and low-frequency transmitter release. The muscle fibers used in this study were removed from a region of the muscle in which slow axon EPSPs are less than $0.5 \mathrm{mV}$ at $1 \mathrm{~Hz}$. Yet, the slow axon has 2-3 times more synaptic membrane per unit length of terminal, and was found in $80 \%$ of the sections in which a fast axon terminal was present. Thus, the slow axon has at least twice the synaptic area of the fast axon per muscle fiber, yet releases only $1 / 20$ as much transmitter at low frequencies. Other factors-such as density and distribution of calcium channels, or possibly terminal excitability-are apparently responsible for the differences in lowfrequency transmitter release (Atwood and Marin, 1983; Walrond and Reese, 1985). In fact, if increased synaptic size of conditioned fast axon terminals is not accompanied by a parallel increase in calcium channels, the decreased release of transmittcr at low frequencics could be due to a lower density of calcium channels.

Total synaptic membrane area appears to be more strongly correlated with the terminal's maximal rate of transmitter release than with low-frequency release. At high frequencies, terminals of the slow axon show facilitation and are actually capable of releasing more transmitter over time than fast axon terminals. The greater synaptic area may provide more available release sites during periods of high activity. Areas of lower calcium channel concentration may be capable of supporting increased vesicle fusion only during periods of high electrical activity with consequent increased calcium entry.

We found no significant difference in the number of dense bars in the 3 classes of terminal. However, presynaptic dense bars were not as dense and well-defined in these terminals as reported for some other crustacean preparations (Atwood and Jahromi, 1978; Govind and Chiang, 1979; Jahromi and Atwood, 1974; Phillips et al., 1982). They rarely spanned more than a single section and thus could easily have been missed. It is therefore difficult to say whether our data on dense bars actually reflect the number of release sites, as has been proposed for some other preparations (Chiang and Govind, 1984; Govind and Chiang, 1979; Govind et al., 1982).

\section{What triggers the change in terminal morphology?}

The change in terminal morphology is probably caused by the increased activity of the fast excitor axon. The stimulation procedure employed here may activate a few axons other than the fast axon and also causes a temporary increase in closer muscle activity, which subsides with synaptic depression. It could be argued that other axons (i.e., neurosecretory axons) or activity of the muscle fibers induces the changes observed in the fast axon terminal. The possibility that the active muscle provides feedback to the axon terminals to produce this effect appears unlikely, since the slow axon terminals do not change even though they innervate the same fibers as the fast terminals. Recently, we have found that direct stimulation of only the fast axon is sufficient to produce the alteration in neuromuscular synaptic physiology (unpublished observtions). This stimulation was achieved by implanting electrodes at the point of entry of the closer motor branch into the closer muscle and monitoring axon spikes during stimulation. Thus, the increase in fast axon activity is probably mainly responsible for the changes in terminal morphology.

Increased fast axon spike production or increases in neuromuscular synaptic activity are not required to produce the changes in synaptic physiology. Increased subthreshold synaptic input to the central processes of this motoneuron results in a change in neuromuscular physiology similar to that produced by increasing spike production (Lnenicka and Atwood, 1985c). Thus, some of the morphological changes reported here, especially increases in mitochondrial size, may be triggered by changes in the motoneuron's central electrical activity (both sub- and suprathreshold).

\section{References}

Allen, R. D., R. J. Lasek, S. P. Gilbert, A. J. Hodge, and C. K. Govind (1982) Fast axonal transport in lobster axons. Biol. Bull. 163: 379.

Atwood, H. L. (1973) Crustacean motor units. In Control of Posture and Locomotion, R. B. Stein, K. G. Pearson, R. S. Smith, and J. B. Redford, eds., pp. 87-104, Plenum, New York.

Atwood, H. L. (1976) Organization and synaptic physiology of crustacean neuromuscular systems. Prog. Neurobiol. 7: 291-391.

Atwood, H. L., and S. S. Jahromi (1978) Fast-axon synapses in crab leg muscle. J. Neurobiol. 9: 1-15.

Atwood, H. L., and H. S. Johnston (1968) Neuromuscular synapses of a crab motor axon. J. Exp. Zool. 167: $457^{\circ}-470$.

Atwood, H. L., and L. Marin (1983) Ultrastructure of synapses with different transmitter-releasing characteristics on motor axon terminals of a crab, Hyas areneas. Cell Tissue Res. 231: 103-115.

Atwood, H. L., and W. A. Morin (1970) Neuromuscular and axonal synapses of the crayfish opener muscle. J. Ultrastruct. Res. 32: 351369.

Atwood, H. L., G. A. Lnenicka, and L. Marin (1985) Morphological responses to conditioning stimulation in a phasic motor axon of crayfish (Procambarus clarkii). J. Physiol. (Lond.) 365: 26P.

Bailey, C. H., and M. Chen (1983) Morphological basis of long-term habituation and sensitization in Aplysia. Science 220:91-93.

Chiang, R. G., and C. K. Govind (1984) Decrease in transmitter output and synaptic ultrastructure at lobster neuromuscular terminals with decentralization. Brain Res. 299: 265-279.

Dreyer, F., K. Peper, K. Akert, C. Sandri, and H. Moor (1973) Ultrastructure of the 'active zone' in the frog neuromuscular junction. Brain Res. 62: 373-380.

Eisenberg, B. R., and G. Salmons (1980) Ultrastructural correlates of fibre type transformation in rabbit skeletal muscle. J. Physiol. (Lond.) 301: 16P.

Frederic, J., and M. Chevremont (1952) Recherches sur les chondriosomes de cellules vivantes par la microscopie et la microcinematographie en contraste de phase. Arch. Biol. 63: 109-132.

Garey, L. J., and J. D. Pettigrew (1974) Ultrastructural changes in kitten visual cortex after environmental modification. Brain Res. 66 : 165-172.

Govind, C. K., and R. G. Chiang (1979) Correlation between presynaptic dense bodies and transmitter output at lobster neuromuscular terminals by serial section electron microscopy. Brain Res. 161:377388.

Govind, C. K., D. E. Meiss, and J. Pearce (1982) Differentiation of identifiable lobster neuromuscular synapses during development. $\mathrm{J}$. Neurocytol. 11: 235-247.

Grafstein, B., and D. S. Forman (1980) Intracellular transport in neurons. Physiol. Rev. 60: 1167-1282.

Greenough, W. T., R. W. West, and T. J. DeVoogd (1978) Subsynaptic plate perforations: Changes with age and experience in the rat. Science 202: 1096-1098.

Hill, R. H., and C. K. Govind (1981) Comparison of fast and slow synaptic terminals in lobster muscle. Cell Tissue Res. 221: 303-310.

Holtzman, E., A. R. Freeman, and L. A. Kashner (1971) Stimulation- 
dependent alterations in peroxidase uptake at lobster neuromuscular junctions. Science 173: 733-736.

Itoh, K., A. Konishi, S. Nomura, N. Mizuno, Y. Nakamura, and T. Sugimoto (1979) Application of coupled oxidation reaction to electron microscopic demonstration of horseradish peroxidase: Cobaltglucose oxidase method. Brain Res. 175: 341-346.

Jahromi, S. S., and H. L. Atwood (1974) Three-dimensional ultrastructure of the crayfish neuromuscular apparatus. J. Cell Biol. 63: 599-613.

Lasek, R. J., and S. T. Brady (1982) The axon: A prototype for studying expressional cytoplasm. Cold Spring Harbor Symp. Quant. Biol. 46: 113-124.

Lehninger, A. L. (1970) Mitochondria and their neurofunction. In The Neurosciences Second Study Program, F. O. Schmitt, ed., pp. 827839, Rockefeller University Press, New York.

Lnenicka, G. A., and H. L. Atwood (1985a) Age-dependent long-term adaptation of crayfish phasic motor axon synapses to altered activity. J. Neurosci. 5: 459-467.

Lnenicka, G. A., and H. L. Atwood (1985b) Long-term facilitation and long-term adaptation at synapses of a crayfish phasic motoneuron. J. Neurobiol. 16: 97-110.

Lnenicka, G. A., and H. L. Atwood (1985c) Long-term adaptation of crayfish neuromuscular synapses does not require an increase in the activity of the altered synapses. Soc. Neurosci. Abstr. 11: 1288.

Martinez, A. J., and R. L. Friede (1970) Accumulation of axoplasmic organclles in swollen nerve fibcrs. Brain Res. 19: 183-198.

Pahapill, P. A., G. A. Lnenicka, and H. L. Atwood (1985) Asymmetry of motor impulses and neuromuscular synapses produced in crayfish claws by unilateral immobilization. J. Comp. Physiol. 157: 461-467.

Phillips, C. E., J. A. Wilson, and D. Mellon (1982) A comparative study by serial electron microscopy of neuromuscular junctions in the dimorphic claws of the snapping shrimp, Alpheus heterocheliss. J. Neurobiol. 13: 495-505.

Rheuben, M. B. (1985) Quantitative comparison of the structural features of slow and fast neuromuscular junctions in Manduca. J. Neurosci. 5: 1704-1716.
Sasaki-Sherrington, S. E., R. Jacobs, and J. K. Stevens (1984) Intracellular control of axial shape in non-uniform neurites: A serial electron microscopic analysis of organelles and microtubules in AI and AII retinal amacrine neurites. J. Cell Biol. 98: 1279-1290.

Schaner, P. J., and M. B. Rheuben (1985) Scanning and freeze-fracture study of larval nerves and neuromuscular junctions in Manduca sexta. J. Neurobiol. 16: 83-96.

Schatz, G., and T. L. Mason (1974) The biosynthesis of mitochondrial proteins. Annu. Rev. Biochem. 43: 51-87.

Sickles, D. W., and T. G. Oblak (1984) Metabolic variation among $\alpha$-motoneurons innervating different muscle-fiber types. I. Oxidative enzyme activity. J. Neurophysiol. 51: 529-537.

Sirevaag, A. M., and W. T. Greenough (1985) Differential rearing effects on rat visual cortex synapses. II. Synaptic morphometry. Dev. Brain Res. 19: 215-226.

Smith, R. A., and M. J. Ord (1983) Mitochondrial form and function relationships in vivo: Their potential in toxicology and pathology, Int. Rev. Cytol. 83: 62-135.

Thompson, C. S., and H. L. Atwood (1984) Synaptic strength and horseradish peroxidase uptake in crayfish nerve terminals. J. Neurocytol. 13: 267-280.

Titmus, M. J. (1981) Ultrastructure of identified fast excitatory, slow excitatory and inhibitory neuromuscular junctions in the locust. $\mathrm{J}$. Neurocytol. 10: 363-385.

Uchizono, K. (1965) Characteristics of excitatory and inhibitory synapses in the central ncrvous systcm of the cat. Nature 207: 642.

Walrond, J. P., and T. S. Reese (1985) Structure of axon terminals and active zones at synapses on lizard twitch and tonic muscle fibers. J. Neurosci. 5: 1118-1131.

Weins, T. J. (1985) Triple innervation of the crayfish opener muscle: The Astacuran common inhibitor. J. Neurobiol. 16: 183-191.

Wernig, A. (1976) Localization of active sites in the neuromuscular junction of the frog. Brain Res. 118: 63-72. 